\title{
O NASCIMENTO DA BIOPOLÍTICA DAS DROGAS \\ E A ARTE LIBERAL DE GOVERNAR \\ http://dx.doi.org/10.1590/1984-0292/1246
}

Tadeu de Paula Souza

Universidade Estadual de Campinas, Campinas, SP, Brasil

\section{RESUMO}

O presente artigo aborda alguns vetores constitutivos da genealogia das drogas enquanto um problema de ordem política, tendo como conceitos centrais biopolítica e governamentalidade. Articulando estes dois conceitos com contribuições de pesquisas sobre a história das políticas de drogas no ocidente, tecemos uma trama que que demarca o processo de constituição das drogas enquanto um objeto de interesse político e estatal. Nessa genealogia da biopolítica das drogas, pudemos explorar aparentes contradições em torno do exercício de fazer viver e fazer morrer que se efetivam através das politicas de drogas. A partir do dispositivo da sexualidade e do tema do racismo pode-se acompanhar as variações e funções estratégicas que as políticas de repressão às drogas cumpriu ao longo do século XX. Desta forma, traçamos um diagrama que emerge com o nascimento do cristianismo e se consolida com a arte de governar liberal. Palavras-chaves: drogas; biopolitica; genealogia.

\section{THE BIRTH OF BIOPOLITICS DRUGS AND LIBERAL ART OF GOVERNING}

\begin{abstract}
This article discuss some vectors constituents of a genealogy of drugs like a politic problem articulating the concepts of biopolitics and governamentality. Articulate these two concepts with the contributions of research on the history of drugs in the West. From these crosses delimit some points that mark the process of incorporation of drugs as an object of political and state mainly. In this genealogy of drugs biopolitics we explore apparent contradictions about life and death. From the sexuality and racism theme can monitor changes and strategic functions that repressive policies on drug fulfilled throughout the twentieth century. Thus we draw a diagram that emerges with the birth of Christianity and is consolidated with the liberal art of government.

Keywords: drugs; biopolitics; genealogy.

\footnotetext{
^Endereço para correspondência: Universidade Estadual de Campinas, Faculdade de Ciências Médicas - Pós-Graduação em Saúde Coletiva. R. Tessália Vieira de Camargo, 126. Cidade Universitária “Zeferino Vaz”. 13083-887. Campinas, SP, Brasil.

E-mail: tadeudepaula@gmail.com
} 
A genealogia da abstinência como norma de conduta ou de governo dos homens deve ser buscada naquilo que Foucault $(2005,2008,2009,2010)$ denominou artes de governar. Os estudos sobre as artes de governar (ou governamentalidade) inauguram novas perspectivas para pensarmos a vida na atualidade como um problema político-estatal e como as drogas passam a compor os diagramas de saber-poder contemporâneo. O poder pastoral cristão, que surge por volta do século III, traz as primeiras experiências disso que Foucault denomina de arte de governar os homens, um governo das condutas em que os usos dos prazeres passam a ser um foco de atenção para se governar os homens. Momento em que a abstinência passa a ganhar alto valor moral e estratégico para o governo dos homens. Mas aquela emergente modalidade de governo se exercia através da rede institucional religiosa exterior ao aparelho de Estado, fora da soberania, embora mantivesse com o poder político uma aproximação e uma articulação. Analisaremos como a consolidação das drogas na forma de um problema de ordem político se dará concomitantemente a estatização de tecnologias de governo, que incidem sobre o modo como as pessoas vivem. Processo pelo qual a abstinência vai deixando de ser uma norma exclusivamente religiosa para se tornar também uma norma médico-jurídica.

Segundo Foucault, o poder pastoral cristão se exerce a partir de três eixos fundamentais: salvação, lei e verdade. A salvação, uma vez não ser uma novidade do cristianismo, encontra uma nova formulação entre os cristãos, pois passa a ser direcionada ao mesmo tempo para a comunidade e ao indivíduo, para o rebanho e para a ovelha. O poder pastoral desenvolveu uma tecnologia direcionada para a proteção e preservação do rebanho, a partir do acompanhamento individualizado de cada um. Cabe ao pastor fazer um relato detalhado, a partir de uma vigília permanente dos méritos e deméritos de cada pessoa que compõe a sua comunidade: falhas e virtudes, intenções e pensamentos, em suma, um governo detalhado de todos e de cada um de forma a conduzir os homens à salvação e à verdade. Trata-se de um modalidade de governo das condutas que é ao mesmo tempo totalizante e individualizante.

A segunda novidade do poder pastoral é o modo específico pelo qual a lei se torna uma "instância de obediência pura" (FOUCAULT, 2009, p. 230), ao contrário dos gregos entre os quais, grosso modo, podemos dizer que a categoria geral de obediência não existia. Os meios pelos quais os gregos deixavam-se conduzir por outro eram exclusivamente a partir do respeito à lei e às decisões das assembleias. O segundo meio usado pelos gregos era a retórica, através da qual os gregos se seduziam a fazer algo, a se deixar conduzir, mas com a finalidade de se alcançar o domínio de si. Tratava-se de uma obediência parcial, na medida em que visava não um estado permanente de dependência, mas a conquista da autonomia e governo de si.

A instauração de um regime de obediência pastoral recoloca a relação com a lei como algo completamente novo. Melhor dizendo, a relação com a lei é substituída por uma relação de obediência, uma vez que os homens devem ser guiados não por uma lei, mas pela vontade de Deus. A lei da polis é substituída pela Lei dos céus. Cabe ao pastor saber esta vontade e tratar cada caso como 
único e singular. A novidade, segundo Foucault (2009, p. 231) não consiste na obediência em si, mas no fato de que esta relação individual de obediência deve ser estabelecida a partir de uma "dependência integral".

A “dependência integral” é uma relação de submissão não a uma lei, nem a uma norma, mas de um indivíduo a outro indivíduo. A obediência é uma finalidade em si mesma e o cristão deve obedecer, aceitar e ser dirigido para as coisas espirituais, bem como para as coisas materiais e para a vida cotidiana. Foucault indica um conjunto de exemplos de boa obediência, que se aplicava mais intensamente aos monges, mas também aos homens comuns.

Outra característica da relação com a lei no cristianismo - a obediência integral não é finalizada, leva pura e simplesmente ao estado de obediência. Este estado, também denominado de humildade, implica uma renúncia da vontade própria. "A finalidade da obediência é mortificar sua vontade, é fazer que sua vontade como vontade própria morra, ou seja, que não haja outra vontade a não ser a vontade de não ter vontade.” (FOUCAULT, 2009, p. 235).

A terceira novidade do pastorado cristão é a relação com a verdade implica num exercício constante e minucioso de desvelar uma verdade oculta que se encontra no interior de cada um. A verdade interiorizada que precisa ser permanentemente vasculhada: ao longo de toda a vida se soma a uma obediência integral e a um desvelar que implica em renúncia. Essa descoberta de uma verdade sobre si implica em uma renúncia do que se descobre: os prazeres do corpo e as sensações enganosas da alma.

Os prazeres da carne não são, neste diagrama cristão, um ponto de reflexão ética, eles são um estado permanente e infindável. A associação entre prazer da carne e o "mal" é de tal ordem intrínseca ao sujeito que não é possível escapar desta relação em vida. A salvação só pode ser alcançada em morte, restando em vida delegar a outro a função de desvelar minuciosamente e constantemente os meios pelos quais o estado de abstinência (dos prazeres pecaminosos) deve ser preservado. A associação intrínseca entre prazer e mal, a adoção da abstinência como norma de conduta e a instauração de um estado de vigília e obediência criam as bases de um poder pastoral que será, após séculos do seu surgimento, incorporado por novas tecnologias de poder.

Neste regime de poder, podemos identificar três importantes características que constituem um nascedouro do que Foucault $(2008,2009)$ denominará de arte de governar. A primeira é o homem tornado como objeto de governo. Não se trata de uma modalidade de governo em que a preocupação se direcione exclusivamente com o território ou com o reinado, mas com a constituição de tecnologias de governo dos homens, seus pensamentos, sentimentos e condutas. A segunda é que este governo é ao mesmo tempo individualizante e totalizante, universal e particular: cada um do rebanho é tão importante quanto o rebanho inteiro. A terceira é de um poder que se direciona para as minúcias da vida, para o detalhe, para os pensamentos e sentimentos ao longo de toda a vida. Trata-se, portanto, de um poder que rege a vida na sua intensividade e na sua extensividade. 
Estas novas tecnologias inseridas pela rede institucional cristã que avançou ao longo de toda a Idade Média permitem problematizar o que outrora se anunciava como uma das principais características da arte de governar pastoral: ser um governo de todos os homens e de cada homem em particular. Entretanto, a relação de obediência e a instauração de um estado de renúncia permite evidenciar que este governo individualizado não se faz na direção do fortalecimento deste indivíduo, de sua emancipação e liberdade individual. É um poder que se exerce sobre o indivíduo com a intenção de anulá-lo e inseri-lo no movimento do rebanho. A relação entre o todo e cada um, entre o universal e o singular é definida por uma operação de uniformização. A renúncia de si é uma diretriz para o cuidado individualizado entendido como uma tecnologia para tornar todos igualmente obedientes. Esse exercício de poder singular se exerce na medida em que cada um seja desprovido de uma singularidade em que a ausência de lei é na verdade uma regra maior, a regra da renúncia: "um modo de individualização que não passa pela afirmação do eu, mas ao contrário a sua destruição." (FOUCAULT, 2009, p. 237). A renúncia de si e a dependência integral a outro indivíduo constituem as matrizes históricas que inserem a abstinência (dos prazeres e das paixões) como uma norma para esta arte de governar.

Estas tecnologias e normas que emergem com o poder pastoral fundarão as bases de uma arte de governar os homens. Estas tecnologias serão, ao longo dos séculos, deslocadas e apropriadas por outros regimes de poder. O poder pastoral se estenderá até o limiar do surgimento dos Estados Modernos, onde novas racionalidades passam a inserir novas tecnologias de governo da vida que ressignificam o exercício do poder pastoral, mas não o anulam.

Parece-me que o pastorado esboça, constitui o prelúdio do que chamei de governamentalidade, tal como esta vai se desenvolver a partir do século XI. Ele preludia a governamentalidade de duas maneiras. Pelos procedimentos próprios do pastorado, por esta maneira, no fundo, de não fazer agir pura e simplesmente o princípio da salvação, o princípio da lei e o princípio da verdade, por todas as espécies de diagonais que instauram sob a lei, sob a salvação e sob a verdade, outros tipos de relações. É por aí, portanto, que o pastorado preludia a governamentalidade. E preludia também a governamentalidade pela constituição tão especial de um sujeito, de um sujeito cujos os méritos são identificados de maneira analítica, de um sujeito que é sujeitado em redes contínuas de obediência, de um sujeito que é subjetivado pela extração da verdade que lhe é imposta (FOUCAULT, 2009, p. 244).

Foram estas as principais características que lançaram o poder pastoral como primeira forma de governo das condutas dos homens, definida por Foucault como uma arte de governar. A relação com a obediência, com a lei e com a verdade inaugurada pelo cristianismo inseriu a vida dos homens, de cada homem e de 
todos os homens a um só tempo, como objeto de governo pela primeira vez na história do Ocidente. É neste percurso de constituição histórica que podemos ver que a abstinência, antes de ser uma norma médica e jurídica, é uma norma religiosa.

O poder pastoral cristão não tem na atualidade o mesmo estatuto de racionalidade geral das condutas que teve ao longo da Idade Média. Entretanto não se pode falar que tenha sido superado. Como afirma Foucault (2009, p. 199) "houve revolução antifeudal, nunca houve uma revolução antipastoral. O pastorado ainda não passou pela revolução profunda que o teria aposentado definitivamente na história".

Entretanto, que relações podemos extrair entre o governo pastoral dos homens e a constituição das drogas como um mal a ser combatido? Uma resposta mais óbvia seria a própria relação entre drogas e prazer que passa a ser foco de interdição para o cristianismo se estendendo e se intensificando até a Idade Média. A outra resposta, que não exclui a anterior, seria o processo de uniformização das condutas imprimido pelo poder pastoral. A operação de unificação territorial e cultural operada pelo cristianismo implicou numa perseguição religiosa que teve efeitos diretos sobre rituais que utilizavam substâncias que alteram o estado de consciência. $\mathrm{O}$ etnocentrismo cristão foi acompanhado de um genocídio em escala global. A única droga permitida pela igreja, o vinho, tinha função ritualística, tendo mais valor simbólico do que propriamente uma busca por efeitos alterados da consciência. (ESCOHOTADO, 2005; ARAUJO, 2012). Diferentes deuses foram transformados em um único Deus, as diferentes substâncias sagradas foram tornadas numa única (vinho como sangue de Cristo) e as diversas seitas perseguidas para a oficialização em uma única religião que tinha o confessionário como dispositivo privilegiado para a vigília permanente das condutas.

A caça às bruxas se intensificou durante a Inquisição e colocou desde aquela época um conjunto heterogêneo de substâncias sob o prisma do mal. O governo das condutas desempenhado pelo poder pastoral produziu efeitos específicos sobre o governo das drogas uma vez que elas estavam diretamente atreladas a seitas e rituais de cura que foram intensamente perseguidos. Mas o alcance em relação às drogas é apenas uma parte deste governo mais amplo das condutas e da construção de uma subjetividade da renúncia e da obediência.

Por quais redes institucionais o poder pastoral foi absorvido? Que estratégia dentro de um novo regime governamental ele passou a ocupar? Serão estas análises que nos permitirão entender o lugar da abstinência como norma médica e jurídica, na atualidade, e sua função estratégica no governo da vida dos homens.

A história do poder pastoral é a história da consolidação da norma da abstinência enquanto regime de verdade sobre o prazer e o desejo da carne, logo da própria noção de sujeito da renúncia. Logo, a genealogia do poder pastoral é a história da construção de um regime de verdade sobre o corpo e a subjetividade que serviram de moldura para que novas tecnologias de poder transformassem as drogas de um problema moral-religioso para um problema político e estratégico para os Estados Modernos. Nesse sentido o poder pastoral é ao mesmo tempo o prelúdio de 
uma arte de governar e um prelúdio do que chamaremos de "dispositivo drogas": drogas como um problema político que agencia um conjunto de relações de saber e poder que passam a cumprir uma função estratégica para governo das populações.

Problematizaremos a consolidação das drogas como um problema de ordem política, a partir das mudanças operadas pelo dispositivo da sexualidade, em que o prazer da carne vai deixando de estar exclusivamente regido pelo signo do mal passa a ser substituído por outro signo: a doença. Processo este operacionalizado por um conjunto de dispositivos, em que a verdade sobre o corpo passa a ser regulada não só pela religião, mas também pelo saber médico. Dentre um conjunto de práticas, Foucault destaca duas: o confessionário e o exame.

\section{Sexualidade}

As análises sobre o nascimento de uma medicina social no século XVIII (FOUCAULT, 2011a, 2011b) e da prática médica do exame no século XIX, em torno do dispositivo da sexualidade (FOUCAULT, 2001) permitem verificar a passagem histórica em que o poder pastoral foi inserido num novo modo de circulação do poder, em que a produção de uma verdade sobre os prazeres deixava de ser restrita ao exercício da igreja cristã. A emergência da saúde como problema de ordem pública e de utilidade econômica para organização da força de trabalho inseriu o corpo e a sexualidade em um novo diagrama de poder.

Esta passagem ganha mais consistência quando as análises de Foucault o conduz a um novo objeto político: a população. Os estudos sobre o governo das populações europeias do século XVIII conduzem o pensamento de Foucault a integrar as análises que partiam de dispositivos específicos para um regime geral de governo que, em última instância, constitui o que esse autor denominou de governamentalidade estatal. Os estudos sobre a governamentalidade, ou genealogia do Estado (moderno), permitem verificar uma articulação mais ampla do poder pastoral num regime governamental. Governamentalidade é antes um índice do método empregado por Foucault para se analisar a formação do Estado. Foucault $(2008,2009)$ se recusa a pensar o Estado como uma categoria universal, como uma unidade que o levaria a estudar suas estruturas e funções internas e a partir dessas verificar suas variações e formas constituídas. Ele propõe o inverso: analisar o Estado a partir de práticas, de racionalidades, de tecnologias de poder que vão dando ao Estado o estatuto de universal estrutural. Este conjunto de racionalidades, mais ou menos anterior e exterior ao próprio Estado, compõe o problema geral da arte de governar ou governamentalidade.

Esta forma de análise que coloca lado a lado subjetividade e Estado, indivíduo e população, vida e disciplina, se contrapõe ao método dialético que propõe a solução de problemas ou sistemas contraditórios através de uma equação geral que unifica os pontos, que se totaliza numa solução universal. Esse modo de analisar a formação dos Estados Modernos europeus implica numa genealogia de práticas heterogêneas que não se resolvem por uma equação que as unifica e totaliza, mas que ora se conectam, ora se articulam, ora se modificam mutuamente. $\mathrm{O}$ 
Estado não é, portanto, tomado como uma máquina que soluciona, na medida em que unifica, mas como um campo governamental que mantém atuante diferentes tecnologias que podem produzir contradição, falhas e disputa.

$\mathrm{O}$ grande crescimento populacional vivido pelos emergentes Estados Europeus no final do século XVIII, fez surgir a "população" como uma realidade política. Fenômenos como doença, natalidade e mortalidade passaram a ter função capital para organização da vida para a produção capitalista. O conhecimento sobre a dinâmica populacional, principalmente a partir da estatística e da epidemiologia, ampliou as margens de intervenção sobre os diferentes modos de vida. A população, tornada um objeto de estudo e intervenção, analisada por meio de um conjunto de variáveis verificáveis matematicamente, colocou a saúde como um campo de saber-poder determinante para o bem-estar social. A emergência da população como finalidade de governo instituiu a saúde e o bem-estar físico como objeto de interesse e intervenção do poder político. Esta nova forma de governo dos homens não se exerce principalmente para castigar e punir, "mas para ajudá-los, se necessário coagi-los, a garantir sua saúde. O imperativo da saúde sendo então: dever de cada um e objetivo geral" (FOUCAULT, 2011a, p. 361).

A emergência da população como campo de intervenção estatal, lançou a medicina como importante matriz de normatização social e condução da vida individual e coletiva. "A importância repentina que a medicina ganhou no século XVIII tem seu ponto de origem ali onde se entrecruzaram uma nova economia analítica da assistência e a emergência de uma política geral da saúde" (FOUCAULT, 2011, p. 362). Demógrafos e estatísticos começaram a estudar problemas como prostituição, taxa de natalidade, precocidade e frequência das relações sexuais, incidência das práticas anticoncepcionais, celibato e proibições, etc. A sexualidade surgiu como um elemento-efeito da expansão de um poder em que a saúde e o bem-estar de cada indivíduo e da população tornam-se matérias de novas tecnologias de governo. Identificados "cientificamente" os motivos pelos quais a sexualidade seria um perigo para a vida, estavam autorizadas intervenções higienistas de saúde pública sobre o conjunto da população.

O nascimento de uma medicina social (FOUCAULT, 2011b) veio acompanhado de uma sofisticação da prática clínica, para a qual a sexualidade ganhou um papel fundamental no desenvolvimento de um poder que tem como objeto a vida: um biopoder. Observa-se, no século XVIII, em alguns estados europeus, uma apropriação do discurso sobre o desejo sexual do campo exclusivamente moral-religioso para o campo de uma produção científica e empírica.

Foucault (2001) busca entender de que modo a sexualidade não foi somente um ponto de interdição moral para a sociedade burguesa emergente. Sua pesquisa se direciona a partir da seguinte questão: como que, a partir de uma suposta repressão, se produziram estudos, análises e discursos sobre a sexualidade nunca antes vistos? A repressão não é a faceta mais importante para se compreender a sutileza do exercício do poder, pois só indica a dimensão negativa do poder: poder-repressão, poder-dominação, deixando de fora o que se produziu além da repressão em si. O que Foucault evidencia é que o dispositivo de sexualidade 
produz uma verdade que passa a ser imposta ao sujeito, uma verdade que precisa ser acessada pela fala. Ou seja, é um dispositivo que se apoia e reitera a noção de uma sexualidade reprimida para dele extrair algo diferente do que a repressão, algo que Foucault chama de governo das condutas, um acompanhamento de um desenvolvimento sexual inventado pelo próprio saber médico, que passa a definir e distinguir desenvolvimento normal e desenvolvimento patológico. A repressão moral-religiosa é um componente para a constituição de um dispositivo da sexualidade, mas ela não totaliza e define a política sobre o corpo, sobre os prazeres e sobre a sexualidade. A repressão, ou noção de repressão, é um ponto de apoio para que uma tecnologia de governo não repressiva se exerça. A repressão, mais do que reprimir a sexualidade, cria a própria noção de sexualidade, que desde o seu nascedouro é produzida como algo a ser revelado, porque reprimido. Como afirma Foucault (2001), conhecemos a sexualidade desde o século XVIII e o sexo desde o século XIX, antes disso, tínhamos somente a carne.

O dispositivo da sexualidade induz, condiciona, produz o próprio objeto sobre o qual incidirá. A sexualidade, desde o início, é um objeto que é ao mesmo tempo sigiloso e reprimido por um lado e pronto para ser explorado e trabalhado por tecnologias da conduta por outro. Para Foucault, a sexualidade não estava dada antes dos exercícios de poder que a tornaram um problema capital. Ela é produzida enquanto um problema de fato, na medida em que se torna um fator de perigo, descoberta, controle e ameaça para a população. A sexualidade enquanto tal é uma produção histórica e não um componente ou uma verdade da natureza humana que a sociedade se apropriou de tal e qual maneira. A sexualidade, nestes termos, é um objeto construído por tecnologias específicas de saber-poder, que por sua vez constituem um regime de verdade sobre o próprio sujeito. $\mathrm{O}$ dispositivo da sexualidade é um objeto através do qual se produzem novas tecnologias de subjetivação. Fazer genealogia nestes termos implica em uma análise dos processos de constituição de objetos de relevância política e social que possibilitam determinar como os sujeitos devem pensar, agir e sentir. Por isso trata-se de um exercício de poder insidioso, porque não se aplica de forma coercitiva diretamente sobre o homem. Ele incide sobre um objeto, no caso, a sexualidade humana. Esse objeto constituiu uma malha fina entre o poder e os sujeitos, pois ele constituiu um campo de saber e intervenção que se estende até o íntimo das relações humanas.

A necessidade de saber mais sobre a sexualidade humana foi apropriada por discursos "pseudocientíficos" que colocaram a sexualidade sob o signo da irracionalidade. A sexualidade foi definida como uma força vital tão poderosa que a condução da vida em sociedade necessitaria da proliferação de meios adequados para melhor conduzir esta força, até então misteriosa. Ao contrário de outros povos, em que a sexualidade foi objeto de uma "arte erótica", que visava a intensificação do prazer, a moderna sociedade ocidental investiu maciçamente na construção de uma ciência sexual, enquanto tecnologia de governo.

Este novo campo de intervenção inaugurado pelo dispositivo de sexualidade só foi possível em um regime em que a vida se torna objeto de poder e, ao mesmo tempo, foi o que possibilitou que o biopoder se exercesse de forma minuciosa sobre a conduta de cada indivíduo. As análises estatísticas e demo- 
gráficas sobre os comportamentos sexuais constituem uma malha fina sobre a qual se produziu uma importante modulação. As tecnologias totalizantes que se direcionam sobre o conjunto da população se sofisticam na medida em que a sexualidade passa a ser um dispositivo, um ponto de passagem para uma tecnologia que é também individualizante.

Enquanto o século XVIII é marcado pela emergência de um saber estatístico da sexualidade enquanto fenômeno de ordem populacional, o século XIX é marcado pela emergência da sexualidade - enquanto campo de intervenção médico-individualizante. Para os médicos, a sexualidade passa a ser cada vez mais uma espécie de campo a ser desvelado, uma vez ser a chave para se entender melhor a saúde, as doenças e as características de cada indivíduo. A questão posta por Foucault (2001) era identificar como o modelo jurídico-religioso da confissão poderia ser moldado e incorporado por um discurso científico, mesmo que bastardo. A primeira exigência para essa produção de saber era a mudança do lugar da confissão. O consultório médico possibilitou que a confissão fosse sofisticada pela técnica do exame, na qual o conhecimento científico sobre a sexualidade se apoia na exigência do exercício da fala de si. Essa intensificação e adensamento da sexualidade, enquanto um objeto para a ciência, ocorreu a partir da separação entre medicina sexual e medicina do corpo. A sexualidade foi isolada enquanto um "instinto" que potencialmente é fonte de desvios, anomalias e patologias, mesmo que não haja nenhuma evidencia corporal manifesta. $O$ instinto sexual passa a ser entendido como um campo de suscetibilidades a serem desveladas, mapeadas, acompanhadas e corrigidas.

O sexo é a ficção histórica que fornece o elo entre as ciências biológicas e as práticas normativas do biopoder. Ao ser categorizado como uma função essencialmente natural que podia apresentar uma disfunção, ele foi considerado um impulso que tinha que ser contido, controlado e canalizado. Sendo natural, era supostamente externo ao poder. Porém, Foucault nos mostra, é exatamente a construção cultural bem sucedida do sexo como uma força biológica que permite ligá-lo as micropráticas do biopoder (DREYFUS; RABINOW, 2010, p. 234).

O exercício do biopoder que se efetiva a partir do dispositivo da sexualidade é verificado pela ramificação e alcance desta nova produção de verdade sobre o indivíduo e sobre a espécie humana. Essa ramificação é analisada por Foucault (2001) a partir de quatro estratégias: a primeira foi observada pela histerização do corpo da mulher, onde a sexualidade comparece como algo difuso e misterioso, tornando o cuidado com o corpo da mulher e o futuro da saúde populacional unidos numa mesma produção discursiva; a segunda se deu pela pedagogização do sexo infantil, através da ampla campanha de erradicação da masturbação,

[...] condenada, desde o início ao fracasso - se o seu objetivo era, de fato, a erradicação da masturbação. Entretanto, se aquela campanha era entendida como produção de poder 
e não como restrição da sexualidade, nesse caso, foi um sucesso admirável (DREYFUS; RABINOW, 2010, p. 226).

A terceira estratégia foi a responsabilização médica e social do casal pela saúde da população. O cuidado com a procriação e proteção contra as influências de uma sexualidade descuidada, coloca o casal aos olhos do Estado, como célula do sucesso ou fracasso de todo corpo social. A quarta e última estratégia é a psiquiatrização dos prazeres perversos. A sexualidade tornada fonte de explicação da perversão e de outros comportamentos humanos abre para um instigante campo de investigação. Os comportamentos em geral passam a ter a perversão sexual como fonte de explicação, em que toda uma escala de normalização e patologização é construída. "Uma vez estabelecida cientificamente uma diagnose para a perversão, tecnologias corretivas - para o bem do indivíduo e da sociedade - podem e devem ser aplicadas" (DREYFUS; RABINOW, 2010, p. 227).

A sexualidade, uma vez constituída como dispositivo de produção de verdade, passa a produzir uma apropriação da prática confessional por novas instituições disciplinares e não religiosas. Esta passagem é operada por uma difusão da prática confessional para outros meios institucionais. Essa difusão da prática confessional, entendida como técnica de incitação a falar sobre o sexo, se desenvolveu coetaneamente a uma preocupação com o bem-estar da população. A prática do confessionário, em que é necessário falar de si, é uma prática de subjetivação que, mais do que produzir uma verdade sobre o sexo, produz uma verdade sobre o sujeito. O projeto pastoral é, assim, ampliado por novas tecnologias que dão continuidade à produção de uma verdade sobre si a partir de um desejo (sexual) que deve ser desvelado por práticas confessionais.

A sexualidade, uma vez tornada um objeto de análise e intervenção da clínica médica, permite que as análises demográficas sejam articuladas a um olhar minucioso dos comportamentos individuais para a delimitação entre o normal e o patológico. A experiência sexual individual patologizada e ao mesmo tempo tornada um problema de ordem pública constitui a passagem para a emergência da sexualidade como um dispositivo de biopoder, um poder que se exerce sobre a vida, individual e populacional. O biopoder é marcado pela emergência da vida como ponto de incidência do poder, a vida do homem na dupla acepção: o homem-corpo e o homem-espécie.

A astúcia e o embaraço trazidos por estas análises implicam na exposição de um tipo de poder que é atual e que, portanto, nos implica a todos. Quem não deseja sua própria saúde e a saúde da população? Quem não deseja o bem-estar físico de sua população? As análises sobre a emergência da saúde e o bem-estar da população como campos de intervenção política devem ser entendidas não por um viés coercitivo do exercício do poder político, mas pela explicitação de uma nova arte de governar que põe o homem como objeto integrante de uma racionalidade de Estado. 
O corpo individual e o conjunto da população passam a ser problemas governamentais, tendo a saúde e o bem-estar como práticas benfazejas. A tradição do pensamento que toma tanto o Estado quanto o poder como coercitivos e repressivos, encontra uma nova formulação a partir destas perspectivas de análise. Trata-se, portanto, de analisar tecnologias de governo da conduta, que não são prioritariamente repressivas, constituídas sob a égide do bem-estar e da saúde individual e da população. Somos lançados, então, a entender de que modo um poder que busca fazer o bem cria tecnologias que normalizam, delimitam pontos, meios e situações em que é necessário usar a força e a imposição. O poder não pode ser visto somente pela sua dimensão coercitiva e dominadora. O biopoder é antes de tudo um poder que "faz viver", um poder insidioso, que conduz e normaliza na medida em que cuida e acolhe.

Porém, em que medida uma história da sexualidade nos ajuda a entender o problema das drogas? O dispositivo da sexualidade carrega uma moldura que serve em grande parte para se entender os problemas atuais sobre as drogas. Apesar das diferenças e especificidades existentes entre "drogas" e "sexo", podemos extrair efeitos mais gerais sobre um processo de mudança do eixo de produção de saber e de tecnologias de conduta sobre os segredos do corpo e dos prazeres. O problema da interdição moral religiosa é recolocado na medida em que a medicina, assim como outras "pseudo ciências", passam a ocupar um lugar de produção de verdade sobre os prazeres do corpo, e o que antes estava situado exclusivamente sob o signo do mal e do pecado, agora passa a estar situado também sob o signo da doença.

As práticas de confissão já não eram exclusividade da religião desde o século XVI, na medida em que foram incorporadas pela pedagogia, nas instituições de internamento e prisões e mais tarde pela medicina. Como vimos, esta última possibilitou articular a confissão às técnicas de exame. As práticas confessionais constituídas em torno do dispositivo da sexualidade instauram uma extensa rede institucional que vai da medicina à justiça e que passa a ter a função de regulação e normalização da vida, produzindo um sujeito portador de uma verdade interior.

A sexualidade é um dispositivo privilegiado para se analisar a construção de tecnologias que interpelam e intervém sobre o desejo e o uso dos prazeres do corpo. O objeto em si (sexualidade) é um meio propício para se analisar a construção de um governo dos homens, de suas condutas, do modo como referem a si próprios, aos seus desejos e pensamentos, ou seja, de uma tecnologia de governo que incide sobre o corpo individual e sobre o corpo da população tendo o desejo como ponto de incidência destas tecnologias confessionais.

Os desejos do corpo desempenham papel central na confissão, desde a época da penitência cristã até nossos dias de hoje. A linguagem e as técnicas empregadas na confissão religiosa tiveram início na Idade Média, prosseguiram durante a Reforma até a atualidade, tornando-se mais refinada de alcance cada vez maior (DREYFUS; RABINOW, 2010, p. 230-231). 
Evidencia-se, então, que o exercício de poder que tem os homens, suas condutas, seus gestos e pensamentos como objetos de intervenção deixa de ser uma exclusividade do poder pastoral cristão. A função de conduzir os homens de forma minuciosa ao longo de toda sua existência passa a ser uma tecnologia de governo político estatizado e não mais de um governo pastoral. Enquanto o tema do prazer era problematizado pela igreja a partir da categoria geral da carne, o biopoder tornou o tema do prazer um campo de investigação científica a partir da categorial geral da sexualidade. O poder pastoral fundou as bases morais e as tecnologias de produção de verdade sobre si. O sujeito moral fundado pela pastoral cristã não desaparece, mas é incrementado, modificado por novas tecnologias do eu, em que "a multiplicação dos objetivos e agentes do poder pastoral enfocava o desenvolvimento do conhecimento sobre o homem em torno de dois polos: um globalizador e quantitativo, concernente à população; o outro analítico, concernente ao indivíduo" (FOUCAULT, 2010, p. 282).

A salvação, que era alcançada após a morte, passa a ser gradativamente ocupada pelas promessas do aqui e agora: bem-estar, saúde e segurança passam a ser as novas modalidades de salvação ainda em vida (FOUCAULT, 2009). De modo geral é a noção de segurança que vai aos poucos ocupando o lugar da salvação.

\section{BIOPODER E A EMERGÊNCIA DO DISPOSITIVO DROGAS}

Até então, no traçado histórico que vimos fazendo com a problematização das ciências da sexualidade, pudemos acompanhar uma produção de verdade sobre o corpo e uma produção dos meios de intervir e modificar condutas. É no contexto dessa espécie de "esquadro pré-moldado" que a política proibicionista de drogas vai ser elaborada, tanto pelos dispositivos da sexualidade quanto pelos dispositivos da delinquência, de tal modo que os usuários de drogas se tornam um novo tipo que transita entre delinquente, louco e pervertido sexual. O usuário de drogas aos poucos foi sendo inserido num campo de investigação sobre a conexão entre prazer e razão.

As drogas como geradoras de um prazer que enlouquece ou geradoras de uma loucura prazerosa seriam, ao longo do século XX, tomadas como uma categoria não só médica como jurídica. Trata-se da conformação de um campo político em que sua consistência não deve ser buscada numa espécie de coerência interna, mas no fato de que a partir das drogas, e suas subdivisões, é possível categorizar os indivíduos e repartir o conjunto da população entre saudáveis e doentes e entre criminosos e não criminosos. Os dispositivos disciplinares: a prisão para o delinquente, o hospício para o louco, e as ciências da sexualidade não visavam diretamente os usuários de drogas. As drogas, assim como ocorrera com a sexualidade, ainda passaria por um conjunto de articulações de saber-poder para que se tornasse um problema de ordem política, econômica e social. Veremos como a construção das drogas enquanto uma realidade política, a partir da qual é possível criar um regime de visibilidade e dizibilidade, permitiu a junção entre estas duas séries (prazer e delinquência). 
Desdea antiguidade, a bebedeira de alguns éum comportamento reprovado por seus contemporâneos. Mas só no século 18 é que, pela primeira vez, um país identifica o consumo exagerado de álcool como um problema generalizado, com desdobramentos para a saúde pública. O fenômeno aconteceu na Inglaterra, na mesma época em que a Companhia das Índias começava a traficar ópio para a China, e ficou conhecido como a epidemia do gim (ARAUJO, 2012, p. 55).

Parece óbvio que o fenômeno da "bebedeira" tenha se tornado problema para a saúde pública no século XVIII, pois foi também nesse contexto que a saúde pública surgiu, sendo desde o início uma modalidade de intervenção estatal. $\mathrm{O}$ que é menos óbvio é que a saúde pública, entendida como campo exclusivamente médico-epidemiológico, era uma matriz explicativa dos comportamentos e hábitos de vida. É neste âmbito que o problema da "bebedeira" passa pelo crivo do saber médico se tornando gradativamente uma doença.

O processo de disseminação do consumo de bebidas alcoólicas é acompanhado, a partir de então, por uma disseminação do discurso médico como campo de produção de verdade sobre a relação entre o indivíduo e o álcool e outras drogas. A saúde pública é definida, neste momento da história, como campo majoritário de intervenções sobre o corpo da população a partir de um empreendimento maciço de patologização do socius e da polis. A "bebedeira" (na Inglaterra) ou mesmo o uso do ópio (na China) como problemas generalizados, ambos no século XVIII, serviram como ponto de construção de uma política de medicalização dos problemas sociais e de avanço para medidas bélicas de combate as drogas.

Esse fenômeno ganha uma maior expressão nos Estados Unidos ao longo do século XIX, quando movimentos de organizações religiosas atreladas ao discurso médico começam a ganhar forte expressão política. Diversas associações antiálcool se formam e investem em ações diretas em bares numa cruzada civil-religiosa. Embora as associações religiosas "antibebidas" fundassem seu discurso no combate ao mal e as iniciativas médicas atrelassem o fenômeno ao discurso da doença, ambos os movimentos apontavam desde esta época para a estratégia de internação compulsória em instituições asilares. (ESCOHOTADO, 2005; ARAUJO, 2012). Trata-se, portanto, de um movimento emergente não-estatal que foi sendo mobilizado a partir de inciativas locais da sociedade civil americana e que aos poucos foi se estatizando.

Num regime em que a saúde da população ganha relevância política, não tardou para que médicos passassem a compor os quadros da administração pública. Um exemplo deste movimento foi o americano Benjamin Rush que, além de ser um dos pioneiros da teoria do alcoolismo como doença, era presbiteriano e fundador da Sociedade Bíblica da Filadélfia (ARAUJO, 2012). Esse misto de medicina, protestantismo e direito penal compuseram a rede de saber que dariam maior legitimidade para que ações no campo legislativo fossem atreladas a inter- 
venções autoritárias e higienistas. Em 1855, leis que proibiam o consumo e venda de álcool eram adotadas por 13 estados norte-americanos, com previsão de prisão e multa para os infratores (ARAUJO, 2012, p. 57).

Apesar das iniciativas proibicionistas terem iniciado no século XVIII e avançado no século XIX, principalmente no interior da sociedade americana, foi ao longo do século XX que se deu a construção das drogas como um problema de interesse diplomático e militar. As drogas foram aos poucos substituindo a sexualidade como figura central de ameaça, perigo e risco de degenerescência - tanto do corpo individual quanto do corpo populacional. Inseridas desde o mercantilismo em redes internacionais de comércio, possibilitaram que as teorias do desejo como campo de investigação sobre a verdade do sujeito e as ciências da população fossem elevadas ao nível de um problema geopolítico de escala global. O processo político de medicalização e criminalização dos usuários de drogas, ancorado numa moral religiosa, ampliou as redes de biopoder enquanto signo explícito de guerra, resguardando outros interesses menos explícitos.

No macro e micropolítica internacional este movimento pode ser verificado a partir da emergência dos Estados Unidos como potência econômica mundial. O desenvolvimento da política de drogas norte-americana permite ser avaliado no contexto geral do desenvolvimento da política econômica liberal. Sob esta ótica é possível evidenciar como o modelo liberal associou um discurso de não intervenção estatal sobre o mercado com intensificação da intervenção estatal sobre as condutas e hábitos dos indivíduos.

Ao buscar inserir a política de guerra às drogas no processo da construção mais ampla da política econômica norte-americana, poderemos verificar que a dimensão repressiva da política proibicionista compõe uma faceta do governo das drogas e não sua totalidade.

As proposições sobre biopoder permitem entender como as drogas puderam se constituir como um objeto de interesse político: geopolítico (de segurança interna e segurança externa), político-econômico (de mercado) e social (políticas sociais). É sobre o tema da vida que uma política global de drogas pode se apoiar, estender suas redes de controle e expandir as tecnologias de poder. O século XX pode ser narrado pelo processo de intensificação do poder Estatal sobre as drogas. Sob a bandeira de erradicação das drogas, a humanidade vivenciou a um só tempo o fortalecimento de uma extensa rede de repressão e uma intensificação do mercado de drogas, ambos nunca antes vistos na história.

Essa história pode ser dividida entre um período anterior e outro posterior à Segunda Grande Guerra. No campo da geopolítica internacional este movimento pode ser acompanhado pela crescente influência dos Estados Unidos no cenário internacional enquanto uma potência econômica, diplomática e militar. O ponto de partida de um empreendimento geopolítico proibicionista ocorreu em 1902, a partir de uma guerra contra a Espanha em que os norte-americanos conquistaram as Filipinas, local de uso habitual de ópio pela população local. Em 1909, os EUA organizaram a Comissão Internacional do Ópio, em Xangai, na qual o eixo "guerra pela comercialização do ópio" seria substituído gradativamente pelo eixo "guerra 
contra o ópio". O segundo encontro dessa comissão, em Haia (Holanda), em 1911, indicava as intenções de internacionalização da política proibicionista, ampliando o leque de substâncias a serem combatidas. Na convenção de Genebra (1936), período entre guerras, em que os EUA já figuravam como potência mundial, a penalização do uso e do comércio de drogas significou um divisor de águas e fundou as bases legais a serem intensificadas pela ONU do pós-guerra até os dias de hoje.

A cruzada americana antidrogas, iniciada a partir das Conferências do Ópio, aponta para uma das dimensões do modus operandi da política antidrogas. Mas dificilmente essa guerra diplomática teria se transformado num interesse político de Estado se suas bases fossem somente morais e religiosas. A produção da papoula e a comercialização do ópio foram monopólio da Índia do século XVI ao século XVIII. Com a conquista da Índia pela Inglaterra, a Companhia Inglesa das Índias Orientais, passa a ter como principal produto o ópio comercializado para a China. As duas tentativas frustradas do governo chinês de proibir a comercialização do ópio deram origem às duas Guerras do Ópio ( final do século XIX) que resultaram no domínio inglês sobre o porto de Hong Kong e a liberação da importação do ópio. (ESCHOTADO, 2005; LABROUSSE, 2010; ARAÚJO, 2012).

A política de criminalização do ópio foi uma das importantes estratégias das quais os EUA utilizaram para enfraquecer o forte domínio econômico que a Inglaterra exercia sobre o Oriente e ampliar sua base de influência (LABROUS$\mathrm{SE}, 2010)$. Não se trata de concluir que o discurso moral encobria os verdadeiros interesses econômicos da política antidrogas, mas de dizer que estes interesses, igualmente vitais para o fortalecimento da política neoliberal norte-americana, se agenciaram, se apoiaram e se fortaleceram mutuamente. Os interesses morais-repressivos não são menos reais do que os interesses econômicos e diplomáticos. Ambos são vitais para a construção de uma geopolítica das drogas e trazem de forma muito evidente o quanto uma política econômica de laissez-faire pode combinar e se fortalecer com uma política intervencionista e repressiva quando o interesse em questão é o controle social.

O que observamos ao longo do século XX foi que a base de sustentação biopolítica proibicionista serviu como matriz potencial para a construção de diferentes estratégias de intervenção que aliam poder de repressão com interesses econômicos diversos. A política de criminalização das drogas é um capítulo de um processo mundial de legislação internacional que, mais do que legislar valores morais mundialmente válidos, foi um processo de organização do mercado. "Digamos que houve uma juridicação do mundo que deve ser pensada em termos de uma organização de um mercado" (FOUCAULT, 2008, p. 77).

O que deve ser lícito e ilícito dentro do jogo internacional deve-se a interesses de mercado. Mas como poderia num mundo definido pela lógica da livre circulação, as drogas, que eram um mercado em expansão, serem criminalizadas? Só na medida em que as drogas pudessem servir de modelo de ameaça à espécie humana. As primeiras iniciativas antidrogas de interesse internacional foram capitaneadas pelo bispo e advogado Charles Brent, após sua chegada nas Filipinas. Tido como um dos principais articuladores da Comissão Internacional 
do Ópio, se vê em seu discurso oficial a articulação entre moral religiosa e racismo, verificado na carta enviada ao presidente Roosevelt em que condenava um "governo cúmplice da busca de ópio por raças degeneradas" (ESCOHOTADO, 2005; ARAUJO, 2012). O problema geral do racismo e das raças degeneradas foi o alicerce biopolítico que sustentou a associação entre drogas e ameaça à espécie humana. O Estado Moderno não inventou o racismo, mas seu uso dentro do regime biopolítico ganhou contornos inovadores. A associação entre hábito cultural (de "raças inferiores") e ameaça geral à vida foi a matriz discursiva para que diversas tecnologias de poder fossem agregando volume e adensando uma verdade sobre as drogas. Numa sociedade em que a vida é objeto de intervenção política, o direito à morte e à restrição da vida só podem ser atribuídos a alguma coisa que ameace a própria vida, a vida da espécie humana. A noção de raça estabelece um corte no contínuo biológico da espécie humana, uma diferenciação que se hierarquiza entre as raças inferiores e as aças superiores, entre as raças que devem viver e as raças que devem morrer. "Isso vai permitir ao poder tratar uma população como uma mistura de raças ou, mais exatamente, tratar a espécie, subdividir a espécie de que ele se incumbiu em subgrupos que serão, precisamente, as raças" (FOUCAULT, 2005, p. 395).

Ao subdividir a espécie em raças, a teoria da degenerescência complementa a matriz teórica para se classificar as raças inferiores. Segundo esta teoria, elaborada pelos alienistas para se classificar o fenômeno da loucura, as doenças eram transmitidas hereditariamente de gerações em gerações e isso serviu de base para diversas práticas eugênicas. A junção entre a noção de raças com a teoria da degenerescência resultou na fórmula proferida pelo então bispo missioneiro da cruzada internacional antidrogas: as "raças degeneradas" que utilizam o ópio podem contaminar a população branca que veio colonizar a Ásia. O papel do bispo e advogado norte-americano Charles Brent foi o de ser um dos precursores da junção entre o discurso racista e o fenômeno das drogas e se tornou uma fórmula mundialmente cambiável e eficiente. Foi necessário somente que o fenômeno das drogas fosse estrategicamente atrelado aos hábitos de determinados grupos populacionais conforme os interesses políticos e econômicos de dominação. Como veremos, esse mesmo eixo discursivo vem sendo utilizado atualmente para caracterizar o fenômeno do crack como algo proveniente do submundo que invade e ameaça as famílias das classes médias.

Vocês compreendem, em consequência, a importância - eu ia dizer a importância vital - do racismo no exercício de um poder assim: é a condição para que se possa exercer o direito de matar. Se o poder de normalização quer exercer o velho direito soberano de matar, ele tem que passar pelo racismo. $\mathrm{E}$ se, inversamente, um poder de soberania, ou seja, um poder que tem direito de vida e de morte, quer funcionar com os instrumentos, com os mecanismos, com as tecnologias de normalização, ele tem que passar pelo racismo. É claro, por tirar a vida, não entendo simplesmente o assassínio direto, mas também tudo o que pode ser assassínio indireto: o fato 
de expor à morte, de multiplicar para alguns o risco de morte ou, pura e simplesmente a morte política, a expulsão, a rejeição, etc. (FOUCAULT, 2005, p. 306).

Na sociedade americana, a criminalização da maconha, da cocaína e do ópio ganhou forte apelo social a partir da associação entre estas drogas e os mexicanos, os negros e os chineses respectivamente. O proibicionismo aliou interesses geopolíticos globais com o aumento das possibilidades de intervenção na vida das populações. As drogas se tornaram um novo eixo de normalização, de esquadrinhamento, de subdivisões que permite estabelecer distinções estratégicas sobre o conjunto da população. Os dispositivos de poder analisados por Foucault permitiram que as teorias de lutas de classe fossem sofisticadas, evidenciando que os problemas sociais gerados pelo capitalismo eram perpassados por tecnologias de normalização. A partir do eixo da normalização podemos evidenciar como a população não se encontra subdividida pura e simplesmente entre classes. Os micropolítica opera em linhas que não se limitam de forma absoluta as divisões de classe, podendo ora apoiar e reforçá-las, ora ultrapassá-las e abrir outros vetores de exercício de saber-poder e produção de subjetividade.

\section{Conclusões}

A segunda metade do século XX é marcada por uma nova engenharia em que as políticas de drogas precisam ser avaliadas a luz da emergente arte de governar neoliberal (FOUCAULT, 2008, 2009). De modo geral, podemos identificar que a política interna de drogas norte-americana serviu de modelo para todo mundo, e se fundou no mesmo discurso que a política externa: segurança. Seguranças internas e externas passaram a compor campos indiscerníveis e contínuos, em que a soberania entre povos se exerce dentro, fora e principalmente nas fronteiras entre Estados. Imigração, xenofobia, racismo, desigualdades sociais são atravessadas pelo signo das drogas como um vetor que legitima a guerra, o autoritarismo e as práticas de extermínio e exclusão. A construção da noção de segurança interna, ao se direcionar para as drogas, amplia as forças de repressão sobre o eixo raça-pobreza e ao mesmo tempo não se limita ao recorte de classes. Políticas de extermínio passam a ser legitimadas sob o novo e crescente dispositivo "drogas" em que a morte passa a ser justificada em nome da vida. No cenário internacional, as drogas e posteriormente o terrorismo, passaram gradativamente a substituir o comunismo como figura ideológica de ameaça à democracia mundial. (BATISTA, 1998, 2001; NEGRI; COCCO, 2005). A emergência da política global de "guerra às drogas", liderada pelos EUA, ampliou e fortaleceu a economia bélica, fomentando práticas totalitárias em diferentes pontos do planeta, criando no cerne da biopolítica, políticas de extermínio.

Como bem nos atenta Foucault (2005), a morte nestes termos não significa assassínio, mas a construção de estados de morte em vida, situações de privação total de liberdade, situação de exclusão, situações de exposição à morte: seja exposição ao fogo cruzado entre traficantes e policiais, seja a imposição de situ- 
ações de reclusão e internação compulsória. Em todos os casos é o momento em que a população, objeto privilegiado de governo, se encontra com a soberania e o despotismo estatal exercido em nome da vida e bem-estar da própria população.

A opção de tentar resolver os problemas sociais a partir de práticas bélicas tornou a guerra às drogas uma guerra interminável, tanto enquanto política de segurança interna, quanto de segurança externa. (HARDT; NEGRI, 2005). Mesmo que o discurso que constitua uma especificidade sobre o usuário seja médico, numa tendência atual de dividir usuários e traficantes, as práticas voltadas para parcela dos usuários de drogas continuam a ser repressivas e associadas à ação policial, principalmente no Brasil.

Em nome da segurança, a partir dos perigos politicamente construídos, a liberdade poderá ser limitada, controlada e abolida. As drogas permitem ampliar as bases de um poder biopolítico e servir aos interesses de uma lógica liberal:

[...] degeneração do indivíduo, da família, da raça, da espécie humana. Enfim, por toda parte vocês vêm este incentivo ao medo do perigo que é de certo modo a condição, o correlato psicológico e cultural do liberalismo. Não há liberalismo sem a cultura do perigo (FOUCAULT, 2008, p. 91).

A arte liberal de governar faz das drogas um manancial infindável de exploração de verdades sobre perigo e ameaça: do indivíduo com ele mesmo, de um indivíduo com outro e de um coletivo com o indivíduo. A expansão das redes de controle e coerção, dentro da qual as drogas ocupam um lugar estratégico, vão ser a contrapartida e o contrapeso das liberdades.

Dentro deste eixo político-estratégico das artes de governar a população se vê enredada e tomada por reflexões que giram em torno do eixo moral-saúde como ponto para se avaliar os perigos que os usuários de drogas representam para a sociedade, enquanto outros interesses passam despercebidos. Essa cena atravessou todo o século XX e desembocou no século XXI através da eterna reedição de figuras monstruosas e socialmente perigosas. Enquanto no início do século $\mathrm{XX}$ vimos o discurso moralista recobrir os interesses econômicos em torno da proibição do comércio oriental do ópio, no contexto atual brasileiro assistimos às crescentes intervenções nas cracolândias que atualizam esse mix de ampliação de um poder repressivo aliado a interesses econômicos.

A especulação imobiliária, em marcha acelerada no Brasil, coloca o espaço urbano sobre uma nova perspectiva econômica. Centros urbanos, muito embora não seja uma novidade dos dias de hoje, se tornam foco de intervenção policial sobre os que eram outrora indigentes vítimas da miséria: os craqueiros, causadores da desordem e da pecha social.

Entretanto, é necessário analisar que lugar estratégico a política repressiva passa a ocupar num regime em que a subjetividade é moldada a partir do modelo empresa e incentivo ao consumismo. Será que a política repressiva é uma estratégia realmente generalizável numa arte de governar neoliberal? 


\section{REFERÊNCIAS}

ARAUJO, T. Almanaque das drogas: um guia informal para um debate racional. São Paulo: Leya, 2012.

BATISTA, V. M. Difíceis ganhos fáceis. Rio de Janeiro: Instituto de Criminologia Carioca/Freitas Bastos, 1998.

BATISTA, V. M. Drogas e criminalização da juventude pobre. In: ASSOCIAÇÃO BENEFICENTE SÃO MARTINHO (Org.). No mundo da rua. Rio de Janeiro: Casa da Palavra, 2001. p. 44-56.

DREYFUS, H. L.; RABINOW, P. Michel Foucault, uma trajetória filosófica: para além do estruturalismo e da hermenêutica. Rio de Janeiro: Forense Universitária, 2010 .

ESCOHOTADO, A. Historia general de las drogas. Madri: Espasa Calpe, 2005. FOUCAULT, M. História da sexualidade: a vontade de saber. Petrópolis, RJ: Graal, 2001. v. 1.

FOUCAULT, M. Em defesa da sociedade. São Paulo: Martins Fontes, 2005.

FOUCAULT, M. Nascimento da biopolítica. São Paulo: Martins Fontes, 2008.

FOUCAULT, M. Segurança, território e população. São Paulo: Martins Fontes, 2009.

FOUCAULT, M. Sujeito e poder, apêndice da primeira edição (1982). In: DREYFUS, H. L.; RABINOW, P. Michael Foucault: uma trajetória filosófica: para além do estruturalismo e da hermenêutica. Rio de Janeiro: Forense Universitária, 2010. p. 273-295.

FOUCAULT, M. A política de saúde do século XVIII. In: MOTTA, M. B. da. (Org.). Arte, Epistemologia, Filosofia, e História da Medicina. Rio de Janeiro: Forense Universitária, 2011a. Coleção Ditos \& Escritos, v. 7, p. 357-373.

FOUCAULT, M. O nascimento da medicina social. In: MOTTA, M. B. da. (Org.). Arte, Epistemologia, Filosofia, e História da Medicina. Rio de Janeiro: Forense Universitária, 2011b. Coleção Ditos \& Escritos, v. 7, p. 402-424.

HARDT, M.; NEGRI, A. Multidão: guerra e democracia na era do Império. Rio de Janeiro: Record, 2005.

LABROUSSE, A. Geopolítica das drogas. São Paulo: Desatino, 2010.

NEGRI, A.; COCCO, G. Glob $(A L)$ : biopoder e luta numa América Latina globalizada. Rio de Janeiro: Record, 2005.

Recebido em: 04 de novembro de 2013

Aceito em: 22 de setembro de 2014 